\title{
IL-17A deficiency alleviate fluoride-induced injury by inhibiting immune response and apoptosis in testis
}

\author{
Yanyan Li \\ Shanxi Agricultural University \\ Yangfei Zhao \\ Shanxi Agricultural University \\ Jinming Wang \\ Shanxi Agricultural University \\ Min Cheng \\ Shanxi Agricultural University \\ Jundong Wang ( $\sim$ wangjd53@outlook.com ) \\ Changzhi Medical College
}

\section{Research}

Keywords: Fluoride, Interleukin 17A, Testes, Leydig cells, Apoptosis

Posted Date: April 2nd, 2020

DOI: https://doi.org/10.21203/rs.3.rs-19810/v1

License: (c) (1) This work is licensed under a Creative Commons Attribution 4.0 International License.

Read Full License 


\section{Abstract}

Backgroud Reproductive toxicity of fluoride $(F)$ has been verified by epidemiological and experimental investigations. Based on the literature and our recent studies, as well as the reports inferred by sequencing analysis of mice with normal and fluorosis testes, it is suggested that the interleukin 17A (IL17A) signaling pathway may be the key link of the damage in testes of the fluorosis animals. To investigate the role of IL-17A in the process of F-induced testicular injury, we exposed wild type (WT) genotype mice and IL-17A knockout (IL-17A-/-) genotype mice to $50 \mathrm{mg} / \mathrm{L}$ Sodium fluoride (NaF) at 90 days, respectively.

Results From the results, we verified IL-17A played a key role in the exacerbation of testicular injuries in fluoride-exposed animals, and found IL-17A knockdown could evidently ameliorate the lesion of testicular damage, including the improves in semen quality,maintain testicular morphology and reducing the immune response in testis. In addition, our results showed that Leydig cells exposed to $\mathrm{NaF}$ and recombinant IL-17A in vitro displayed both abnormal apoptoses and decreased secretions of testosterone.

Conclusions Altogether, our findings proved that IL-17A deficiency alleviate fluoride-induced injury by inhibiting immune response and apoptosis in testis. This study also provides the mechanism of reproductive toxicity of $\mathrm{F}$, the basis for scientific diagnosis, and possible target drug design.

\section{Background}

Fluoride ( $F$ ) is a highly ubiquitous chemical found in the environment where constant exposures to all individuals occur in a daily basis through various activities[1]. Numerous studies have shown that excessive $\mathrm{F}$ intake can damage human health, including skeletal, digestive, immune, and reproductive systems, especially the testicular tissues[2, 3]. It has been demonstrated that excessive F ingestion had an adverse impact on the hypothalamus-pituitary-testicular axis structure, testicular histology, and quality of semen[4]. Research at the cellular level found excessive fluoride intake can amplify apoptosis, autophagy and even death of germ cells[5]. Intriguingly, using the sequenced RNA transcripts from the testicles of healthy and fluorosis male mice in our study, we found four pathways related to IL-17A signaling that were overexpressed in the testes of fluorosis male mice[6]. This indicates that IL-17A may be the pivotal regulator in the process of excessive fluoride-induced testicular damage in mice.

In our previous studies, we found that fluoride-induced testicular toxicity in mice was associated with inflammatory response by damaging the blood-testes barrier (BTB) through IL-1a[7]. Notably, inflammation of the testes due to excessive $\mathrm{F}$ exposure is associated with autoimmune orchitis where IL17A operates as a key cytokine in the inflammatory process[8]. In testis, excessive IL-17A production can recruit immune cells to the testicular interstitial tissue thus inducing local infiltration of the inflammatory cells and destroying the BTB[9]. The levels of IL-17A in the testes of subfertile and infertile patients with functional and obstructive sperm deficiency are significantly higher compared to those with normal 
fertility[10]. However, the function and mechanism in the increase of IL-17A in the process of fluoride induced testicular damage are not clear.

Based on the researches of male-reproductive toxicity induced by superfluous $F$ in body, we have chosen the testes of mice to evaluate the causative role of IL-17A in the process of fluorosis. In this study, the fluorosis models of wild type (WT) genotype mice and IL-17A knockout (IL-17A-/-) genotype mice were established to estimate the effect of IL-17A deficiency on the degree of testis damage induced by fluoride in mice, including semen quality, testicular morphology and testosterone level in serum. Further, we examined the expressions of IL-17A signaling pathway and its related cytokines to deeply analyze the influence of altered IL-17A defection on the damaged testes in fluorosis animals. Additionally, we conducted in vitro experiments to explore the target cell of IL-17A injury induced by fluoride in testis. We also discussed the valuable application of the animal models and the experimental theory in the context of human health.

\section{Results}

\section{IL-17A is induced in the testes of Fluorosis model}

To characterize which interleukins participated in the testes injury by production of IL-17A, we treated the WT mice fluorosis model with different concentrations of NaF and measured the mRNA expression levels of cytokines associated with IL-17A function and secretion in the testes. In $50 \mathrm{mg} / \mathrm{L} \mathrm{NaF}$ treated group,the mRNA expression levels of IL-17A, IL-17R, IL-6, IL-23, IL-1 $\beta \bigotimes T$ TGF- $\beta$ and TNF- $\alpha$ in the testes of mice were evidently increased compared to the $0 \mathrm{mg} / \mathrm{L} \mathrm{NaF}(P<0.05)$, but no significant changes were observed in the mRNA expression levels of IFN- $\gamma$. In $100 \mathrm{mg} / \mathrm{L} \mathrm{NaF}$ group, the expression of IL-17A, TNF- $a$, IL-23 and IL-1 $\beta$ were significantly increased $(P<0.05)$, and the rest of cytokines have no obvious change. This implies that IL-17A may play a key role in testicular injury induced by $F$ and the increase of IL-17A corresponds to IL-17R, IL-6, IL-23, IL-1 $\beta$, TGF- $\beta$ and TNF- $\alpha$ (Fig.1A). We also measured the IL-17A levels in the interstitial fluid of testes and observed that relative to control the expression of IL-17A increased significantly in $25 \mathrm{mg} / \mathrm{L}$ and $50 \mathrm{mg} / \mathrm{L} \mathrm{NaF}$ groups but not in $100 \mathrm{mg} / \mathrm{L} \mathrm{NaF}$ group from Fig. $1 \mathrm{~B}(P<0.05)$.

\section{Successful establishment of fluorosis animal model}

To verify the success of the animal model of fluorosis, we measured the $F$ content in the bone of the experimental mice. In contrast to the control group, the bone F content in WT and IL-17A-/- mice exposed to $50 \mathrm{mg} / \mathrm{L} \mathrm{NaF}$ showed a significant increase trend $(P<0.001)$. For the body weight gain, the mice in WT $\mathrm{NaF}$ group present a remarkable decrease line $(P<0.01)$. However, there was no distinct statistical change observed in terms of weight gain in IL-17A deficient fluorosis mice. This results indicate that our model of fluorosis is successful establishment (Fig.2A and B).

\section{IL-17A mediates the damage of excessive $F$ to semen quality}


To explore the role of IL-17A in the testes after $\mathrm{F}$ injury, we examined the changes in the semen quality in mice, including sperm count and deformity rate. In comparison to controls, the sperm count displayed a decreasing trend $(P<0.01)$ while the deformity rate presented an evidently increasing trend $(P<0.01)$ in the WT 50 mg/L NaF group, however, no significant changes of semen quality were observed in the IL-17A-/NaF group (Fig.3).

\section{IL-17A mediates the effect of excessive $\mathrm{F}$ to histomorphology and ultrastructure of the testes in fluorosis mice}

We assessed the alterations on the histomorphology and ultrastructure of testes using the H\&E staining and TEM methods, respectively. In the control group, we observed a normal morphology of the testes with spermatogenic tubules and spermatogenic cells arranged neatly. Further, we found abundant spermatozoa in the middle of the seminiferous tubule. In the WT NaF group, the number of spermatogenic cells and spermatozoa were evidently decreased and the distance between the seminiferous tubules was increased. Interestingly, the morphology of testes in IL-17A-/- NaF group was almost parallel to the control (no significant changes), despite the fact that these mice were exposed to $50 \mathrm{mg} / \mathrm{L}$ of $\mathrm{NaF}$ (Fig.4A). By examining the ultrastructure of mouse testes, as shown in Fig.4B we observed some severe pathological alterations of the Leydig cells in the testicular interstitium of mice exposed to $50 \mathrm{mg} / \mathrm{L} \mathrm{NaF}$ for 90 days. In the IL-17A-/- NaF group, we found villi on the edge of Leydig cells and rich lipid droplets in the cells with a normal structure of neighboring cells. However, in the WT NaF group, the lipid droplets in Leydig cells were increased both in size and number, indicating that the secretion of the testosterone was reduced. Also, the marginal villi disappeared with a decrease of the endoplasmic reticulum structure. These results indicate that IL-17A can mediate the effect of excessive $F$ to histomorphology and ultrastructure of the testes in fluorosis mice

\section{IL-17A mediates the effect of excessive $F$ on the testosterone level in serum of fluorosis mice}

Based on the above results, we further evaluated the levels of the testosterone level in serum by ELISA and the testosterone secretion related proteins by western blotting. Fig.5A showed that exposure with 50 $\mathrm{mg} / \mathrm{L} \mathrm{NaF}$ at 90 days resulted in a remarkable decrease of testosterone level in the serum $(P<0.05)$, but the level of testosterone remained normal levels in the testes of IL-17A deficient mice. Moreover, we also measured the expression of testosterone secretion-related proteins in testis in each group. In contrast to the control group, the protein expression pattern of AKR1C3 and CYP11A1 were dramatically reduced in WT NaF group $(\mathrm{P}<0.05$ and $\mathrm{P}<0.01)$, but the SHD protein expression remained unaltered (Fig.5B).

Howevere, after the removal of IL-17A, although the mice received the same dose and time of NaF at the expression levels of these genes were not statistically different from that of the control group. Altogether, these results suggest that knocking out the IL-17A in mice can alleviate the testicular damage caused by F.

F can stimulate downstream proteins in IL-17A signal pathway in the testes of fluorosis mice 
To reveal how IL-17A works in a fluoride-induced testes damage, we examined various downstream proteins potentially involved in the IL-17A signaling pathway. As shown in Fig.6, compared to the control group, the expressions of IL-17A and Act1 were dramatically increased $(P<0.001)$, NF-KB was significantly increased $(P<0.01)$, IL-17R, C/EBP-a, TRAF6 were obviously increased $(P<0.05)$ in the WT NaF group.But these proteins did not showed a visible changein the IL-17A-/- NaF group. These results suggest that $F$ stimulates the testes to produce IL-17A thereby inducing testicular damage by activating downstream proteins involved in the IL-17A signaling pathway.

\section{The effect of IL-17A deficiency on the expression of related cytokines in testis of fluorosis mice}

To investigate the effect of IL-17A knock out on the immune response in testis of fluorosis mice, we test IL-17A cytokines related to IL-17A secretion and function. From the Fig.7, we found that in the testis of WT fluorosis mice, IL-17RC, IL-6, IL-23 and TGF- $\beta$ were remarkably increased $(P<0.01)$, IL-1 $\beta$ and TNF- $a$ were obviously increased expcept for IFN- $\gamma(P<0.05)$ compared to the control. The expression trend of cytokines tested by ELISA in the testis of wild-type fluorosis mice was consistent with that of mRNA detected by PCR in this study. Importantly, When IL-17A was knocked out, the expression level of IFN-y was significantly higher than that of the control $(P<0.05)$, but the rest of cytokines did not present the statistically significant.

\section{IL-17A amplifies apoptosis of testicular interstitial induced by $\mathrm{NaF}$ in vivo}

To explore the mechanism of IL-17A-induced testicular damage in fluorosis mice, we examined the testicular apoptosis through immunohistochemistry (Fig.8). NaF (50 mg/L) exposure for 90 days can obviously increase the expression of caspase-3 and caspase- 9 in the interstitial tissue of testes in WT mice $(P<0.01)$. But for IL-17A-/- fluorosis mice, there was no significant difference in the expression of caspase- 3 and caspase -9 in the testes compared with the control group. These results indicate that Finduced IL-17A production may amplify apoptosis in the testicular interstitial tissue.

\section{IL-17A promotes Leydig cell apoptosis and reduces testosterone secretion in vitro}

We next sought to investigate the effect of IL-17A in the Leydig cells of the testes. Annexin V-FITC/PI apoptotic experiments by FCM was performed to determine the effect of NaF and/or IL-17A in the Leydig cells. The results from Fig.9A showed that $2 \mathrm{mg} / \mathrm{L} \mathrm{NaF}$ and $1 \mathrm{ng} / \mathrm{ml}$ of IL-17A could promote apoptosis, and the combination of IL-17A and $\mathrm{F}$ group mice resulted in a further significant increase in the level of apoptosis occurring in the Leydig cells.

We also analyzed in vitro the expression levels of testosterone secretion-related genes, including INOS, $3 \beta-S H D, 17 \beta-S H D, C Y P 11 A$, and STAR in the Leydig cells by RT-PCR. The results showed that F and IL-17A evidently reduced the expression levels of these genes and the secretion of testosterone, which were both consistent with the results of the in vivo experiments, suggesting that IL-17A could target mainly the Leydig cells in the testes after fluoride damage (Fig.9B). 


\section{Discussion}

Fluorosis is a prevalent disease worldwide and particularly endemic in China, which is one of the countries where $F$ causes serious harm[11, 12]. In 2015, a review reported that $F$ ion concentrations in the groundwater can reach at $48 \mathrm{mg} / L[12]$. This means that drinking water is the main source of excessive $F$ ions, causing fluorosis in humans and animals. Although the exact link between fluorosis and infertility was established as early as 1925 , the mechanisms linking them are poorly understood. Hence, it is very pivotal to evaluate the mechanisms of reproductive toxicity caused by $\mathrm{F}$ using an effective and reliable animal model.

Firstly, we exposed the WT C57B/6J mice to different concentrations of NaF, including 25, 50, and $100 \mathrm{mg} / \mathrm{L} \mathrm{NaF}$ for 90 days. We observed that IL-17A was highly expressed in the testes of mice exposed to $50 \mathrm{mg} / \mathrm{L} \mathrm{NaF}$ and IL-6, IL-23, IL-1 $\beta$, TGF- $\beta$ and TNF- $\alpha$ are closely related to the secretion and function of IL-17A induced by fluoride in testis. We also found that the expression of IL-17A was increased evidently in the interstitium of the testes using ELISA assay. A recent report by Hossam et al suggested that IL-17A mainly exists in the testicular interstitium of azoospermia patients. This is consistent with our results that IL-17A is abundant in the testicular interstitium of the fluorosis model. Although the previous studies has certificated that IL-17A is found mainly in the interstitium of the testes undergoing fluoride stimulation, the mechanisms behind fluoride-induced testicular damage and IL-17A production were not demonstrated. Hence, we selected IL-17A gene knockout fluorosis mice as an available model to gain more insights about fluorosis.

Although low doses of fluoride are beneficial to mammalian teeth and bones, its long-term exposure can cause dental fluorosis and may interfere with bone formation[13]. Therefore, the $F$ content in the skeleton is an important index to determine whether the fluorosis model is successfully established or not. In this experiment, when the mice (WT and IL-17A-/-) were exposed to $50 \mathrm{mg} / \mathrm{L} \mathrm{NaF}$ at 90 days, the F content was significantly abundant in the femur of mice, indicating that the establishment of the animal model of fluorosis was successful.

Earlier studies revealed that the height and weight of children in F-contaminated areas were significantly lower than those in normal areas[14]. Recent works using animal models reported that rats or mice exposed to superfluous $F$ could experience a significant reduction in weight and organ coefficient of liver $[15,16]$. This corroborates with our results, which shows that the weight gain of mice exposed to $50 \mathrm{mg} / \mathrm{L} \mathrm{NaF}$ for 90 days significantly differs from the control group, indicating that excessive $\mathrm{F}$ exposure causes an adverse effect on the growth performance of mice. It should be noted that $F$ did not significantly affect the weight gain of IL-17A deficient mice, possibly the absence of IL-17A antagonizes the damage caused by $\mathrm{F}$ in other tissues.

Studies have shown that excessive $F$ consumption can take adverse effects on semen quality and damage the normal structure of testis $[17,18]$. In our study, the use of different genotype animal models of fluorosis revealed that excessive NaF intake in the testes of WT mice could induce sperm count reduction and increase the rate of abnormal spermatozoa. In addition, it was found that the distance 
between seminiferous tubules increased and the number of cells in spermatozoa and stroma decreased in testis of fluorosis mice[19]. However, IL-17A deficient mice treated with $50 \mathrm{mg} / \mathrm{L} \mathrm{NaF}$ for 90 days could effectively suppress these abnormal changes of semen quality and structure. Furthermore, the TEM were used to study the target of fluoride on testis more accurately, we found that excessive intake of fluoride can damage the normal structure of Leydig cells, and may decrease the ability of testosterone secretion. These results are not only consistent with the previous studies but also proved that functional alterations in IL-17A might play a key role in F-induced testicular damage.

IL-17A, mainly produced by Th17 cells, is an inflammatory cytokine with various functions, such as eliminating pathogenic microorganisms and inducing autoimmune inflammation[20, 21]. IL-17A can also recruit Act1 and TRAF6 by binding to IL-17RA or IL-17RC heterodimer receptor complexes in the process of inflammation[22]. On the one hand, self-ubiquitinated TRAF6 binds to TAK1 complexes and activates IKK complexes, leading to activation of NF-kappa B and MAPK pathways[23]. On the other hand, Act1 also participates in the activation of C/EBP. Activation of NF-kappa B, MAPK, and C/EBP up-regulates the expression of chemokines and cytokines, which both induce immune cell recruitment, inflammatory response, and tissue damage[24, 25]. These findings indicate that the balanced expression of the signaling molecules downstream of IL-17R decides the cellular response. In the WT NaF fluorosis group of our study, we found that the protein levels of IL-17A, IL-17R, Act1, NF-KB, C/EBP-a and TRAF6 presented a sharply upward trend. This means thatIL-17A and its signaling pathway might be involved in regulating the process of testicular damage in fluorosis. Although the mice in the IL-17A-/- group were also exposed to $\mathrm{NaF}$, the related proteins in the IL-17A pathway were largely unaltered compared with the normal mice. Hence, these revealed that F-induced IL-17A production can cause damage to the testes. Our findings corroborate with the results from $\mathrm{Wu}$, who revealed that excessive $\mathrm{F}$ can cause orchitis and damage the normal function of the testes[8].

Secreted by Leydig cells, testosterone can promote and maintain spermatogenesis in the testes[26]. There have many studies have confirmed that excessive fluoride intake can reduce the level of testosterone in vivo and in vitro[27, 28]. Based on our research in this experiment, we also detected the level of testosterone in IL-17A gene knock-out fluorosis mice, and we were surprised to find that the level of testosterone in the serum of this kind of mice was even equal to that of normal mice. We also detected the related proteins of testosterone secretion in mouse testes. The AKR1C3, also called HSD3 $\beta 1$, is responsible for the final step in the biosynthesis of testosterone from androstenedione[29]. Unlike HSD11 11 , CYP11A1 exists in all stages of the Leydig cells and encodes the Cytochrome P450 Family 11 Subfamily A Member 1A[30]. Both AKR1C3 and CYP11A1 are the key rate-limiting enzyme in the process of steroid hormone synthesis. It has been confirmed that excess $\mathrm{F}$ feeding can reduce the activity of AKR1C3 and CYP11A1 in the testes and further inhibit the secretion of testosterone[31]. Our study confirms the previous findings that fluorine can cause a decrease in AKR1C3 and CYP11A1 levels. However, after the knockout of IL-17A in the testes of mice, the expression of AKR1C3 and CYP11A1 returned to the level similar to the normal mice. 
To elucidate the effect of IL-17A deficiency on the testicular immune response of fluorosis mice, we detected the content of IL-17RA, IL-17RC, IL- 6 , IL-1 $\beta$, IFN- $\gamma$, TNF- $\alpha$, IL-23 and TGF- $\beta$ by ELISA. Our current findings showed that in the testicular injury caused by fluorosis, IL-17A and its receptors occurs mainly in the interstitial tissue of testes. Interestingly, IL-17RC was significantly increased in the testis of WT fluorosis mice, but the content of IL-17RA was not significant and this needs further study. Consistented with previous results, the IL-6, IL-23, IL-1 $\beta$ and TGF- $\beta$ were increased in the testis when the WT mice exposed $50 \mathrm{mg} / \mathrm{L} \mathrm{NaF[6]}$. There have a investigation also indicated that the mRNA levels of TGF- $\beta$, IL-1 $\beta$, IL-6, and IL-21 up-regulated intestis after F exposure[32]. More importantly, after knockout of IL-17A, the expression of IL-6 and IFN-yin testis was still increased compared with the control group. This result suggests that the IL-17A deficiency can alleviate fluorosis by reducing the immune response in testis and damage of IL-17A to testis may not related to IL- 6 and IFN $-\gamma$.

There are numerous innate immune cells in the interstitium of testes, such as T cells, macrophages, NK cells, etc[33]. Nevertheless, it is not clear which immune cells secrete IL-17A under the stimulation of F. By combining the PCR and ELISA results on IL-17A secretion related factors, we found that the secretions of IL-6, IL-23, and IL-1 $\beta$ were increased in testicular fluorosis WT in mice. However, after knockout of IL-17A, the expression of these inflammatory factors except IL- 6 did not increase. This suggests that the expressions of IL-6, IL-23, and IL-1 $\beta$ depend on the increase of IL-17A in the process of fluoride-induced testicular injury. Previous findings showed that the increase of IL-17A can promote the secretion of IL- 6 in some inflammation and cancer[34]. Also, $\gamma \delta$ T cells can produce IL-17A upon stimulation by IL-1 $\beta$ and IL23 in the testes[35, 36]. Featured by the expression of $\gamma \delta$ TCRs and secreted extensive pro-inflammatory cytokines, $\gamma \delta T$ cells are usually the main providers of IL-17A in various models of inflammatory diseases[37, 38]. Besides, in vitro studies have confirmed that the secretion of IL-17A will increase when үठ T cells bind to IL-23[39]. Therefore, we speculated that among the cytokines related to IL-17A, the expressions of IL-1 $\beta$ and IL-23, which were supposed to stimulate $\gamma \delta$ T cells to secrete IL-17A, would be sharply up-regulated in the process of a testicular injury caused by $\mathrm{F}$, indicating their role in IL-17A production. Testes have established effective self-protection through its immunosuppressive microenvironment, which is free from pathogens and inflammatory damage[40]. Once the microenvironment of the testes is imbalanced, it may lead to the occurrence of inflammation and lesion[41]. The overexpression of IL-17A, IL-6, IL-1 $\beta$, and IL-23 may change the immunosuppressive microenvironment of the testes, causing testicular damage.

The changes of testicular environment caused by abnormal expression of cytokines can induce excessive apoptosis[42, 43]. Hence, we detected the expression of two key apoptosis proteins in testis, caspase-3 and caspase- 9 acted an irreplaceable role in apoptosis[44]. Caspase- 9 can be activated by self-cutting after being stimulated, followed by induction of the caspase cascade reaction to activate caspase-3[45]. As a key death protease downstream of the apoptosis pathway in mammalian cells, caspase-3 can shear multiple polymerases and lead to apoptosis[46]. Numerous studies have confirmed that excessive $F$ intake can lead to apoptosis of multiple tissues and cells[47, 48]. Furthermore, Yan et al showed that $F$ can induce the apoptosis of singular cells by accelerating the release of caspase-3 and caspase-9[49]. In our study, we found that excessive NaF exposure can indeed boost the expression of caspase-3 and 
caspase-9. Interestly, with the deletion of IL-17A, the expression of caspase-3 and caspase-9 in the testes have shifted as well. Notably, the fluoride-induced apoptosis in the testicular interstitium can be inhibited after knocking out the IL-17A. In addition, the observation from the immunohistochemical chart pointed out the apoptosis of testes mainly occurs in the interstitial tissue. We also demonstrated that $\mathrm{NaF}$ treatment in vivo can stimulate a significant decrease in testosterone secretion, however, IL-17A-depleted mice exposed to $\mathrm{NaF}$ can restore the ability to secrete testosterone. Therefore, we speculated that Leydig cells may be a target in the process of IL-17A-mediated fluoride-induced testicular damage.

We observed that fluoride-induced testicular damage occurs mainly in the Leydig cells. Therefore, we chose Leydig cells as our target to further elucidate the role of $F$ in inducing reproductive toxicity. Leydig cells, referred to as interstitial cells, play a critical role in the testicular endocrine and immunologic systems[50]. The main function of Leydig cells is endocrine because they can secrete a high level of androgens[51]. Previous studies reported that excessive F exposure can lead to proliferation, autophagy, and apoptosis of the Leydig cells[52]. In the present study, fluoride and IL-17A can promote late apoptosis of the Leydig cells, and can significantly reduce the expression of genes involved in testosterone secretion. Therefore, we hypothesize that the increase of IL-17A after fluoride exposure can cause Leydig cell apoptosis leading to testosterone reduction, which will then negatively impact the semen quality. Our results do not only indicate that Leydig cells are susceptible to F-related changes in the testes, but also prove the antagonistic role of IL-17A during the process of testicular damage caused by F.

\section{Conclusions}

In present study, the establishment of a simple $\mathrm{F}$ injury model was proved to be successful by detecting the fluorine content in bone. By establishing the fluorosis model of IL-17A deficiency, we demonstrated that IL-17A and its signaling pathway might be involved in the regulation of testicular damage in fluorosis animals and the deletion of IL-17A could abrogate the lesion of testicular fluorosis, including the testicular morphology and semen quality. Additionally, excessive $F$ intake may evoke abnormal apoptosis of the Leydig cells and decrease the ability of testosterone secretion through IL-17A in the testes of mice. Therefore, we concluded that IL-17A deficiency alleviate fluoride-induced injury by inhibiting immune response and apoptosis in testis (Fig.10). Although the source of IL-17A stimulated by F needs to be further explored, this study suggests that IL-17A could be a new target for the treatment of testicular fluorosis.

\section{Methods}

\section{Establishment of animal model}

To verify the effect of excessive $F$ exposure on the expression of IL-17A in mouse testes, we selected 8week old wild type (WT) genotype male mice (C57B/6J) and randomly divided into four groups (13 mice per group). The mice were fed with different concentrations of $\mathrm{NaF}$ in distilled water $(0,25,50,100 \mathrm{mg} / \mathrm{L})$ plus a normal diet at 90 days. To explore the effect of $F$ on the testes after IL-17A deficiency, 8-week old 
male mice were divided into three groups (13 mice per group) : one control group (C group): WT mice, normal diet and distilled water; two fluorosis group (WT NaF group and IL-17A-/- group) : including WT mice (C57B/6J) and IL-17A-/- mice (C57B/6J background), treated with normal diet and distilled water with $50 \mathrm{mg} / \mathrm{L} \mathrm{NaF}$ for 90 days; After 90 days of $50 \mathrm{mg} / \mathrm{L} \mathrm{NaF}$ exposure, the general observations in all mice were performed (mice were weighed every one week), and the animals were euthanized with $1 \%$ sodium pentobarbital by intraperitoneal injection, as stated in the ethics requirement. The semen quality of mice was immediately assessed by examining the testes and extracting the semen, which was quickly stored in liquid nitrogen for the collection of total RNA and protein.

\section{Quantitative reverse transcriptase-PCR}

Total RNA was obtained from the testes using the Trizol reagent, with procedures followed the manufacture's protocol (Solarbio, China). The total RNA was reverse-transcribed using PrimeScript ${ }^{\text {TM }}$ RT $^{T}$ reagent Kit with gDNA Eraser (Takara, China). Real-time fluorescence quantitative reverse transcription polymerase chain reaction was performed using the QuantStudio ${ }^{\mathrm{TM}} 6$ and 7 Flex (Applied Biosystems ${ }^{\mathrm{TM}}$, USA). The primers of the analyzed genes are shown in table 1. QRT-PCR was performed in $10 \mu \mathrm{L}$ of reaction mixture based on a previously described protocol and the expression levels of the target genes were performed by the $2-\Delta \Delta \mathrm{Ct}$ method.

\section{Collection of interstitial fluid}

The interstitial fluid was collected as follows: an incision in the capsule of testes was performed and the drained fluid was gathered at $4{ }^{\circ} \mathrm{C}$ in the presence of protease inhibitors with $1 \mathrm{mM}$ Phenylmethylsulfonyl fluoride (PMSF) and $10 \mu \mathrm{g} / \mathrm{ml}$ aprotinin; after $16 \mathrm{~h}$, the interstitial fluids were stored at $-70^{\circ} \mathrm{C}$ prior to the analysis of IL-17A protein level.

\section{Quantification of F levels in the femur of mice}

After $F$ exposure period, the femurs from mice were removed and the $F$ content in each sample was determined by $\mathrm{F}$ ion selective electrode method[40]. In brief, the Total lonic Strength Adjustment Buffer (TISAB) was prepared and femurs from mice were dry-ashed by utilizing Muffle furnace for $5 \mathrm{~h}$ at 550Added to the diluted hydrochloric acid ( $5 \mathrm{~mL}$ of $0.5 \mathrm{M} \mathrm{HCl}$ per sample), bone cinder $(20 \mathrm{mg})$ was put in a small plastic ping. The solution of the bone specimen was mixed with TISAB. The final solution was used to measure the fluoride concentration by fluoride ion selective electrode.

\section{Detection of sperm count and deformity rate}

Aliquots of sperm suspensions were prepared for the determination of sperm quality using the method previously described[53]. Briefly, $10 \mu \mathrm{L}$ sperm suspension was placed on erythrocyte counting plate (Neubauer Chamber) and a small drop of semen was applied on the slide to calculate the rate of sperm deformity (at least 200 sperms per sample were count). Microscopically, most of the spermatozoa were normal but some were abnormal showing head deformity (large head, thin, slender, round, obscure outline, wrinkle, defect, double head, etc.), neck deformity (neck enlargement, slenderness, flexion, 
incompleteness, bisomy, etc.), middle tail deformity (enlargement, slenderness, flexion, incompleteness, bisomy, etc.), and tail deformity.

\section{Histopathological and Ultrastructural analyses}

The testes were stabilized in Bouin's solution for $12 \mathrm{~h}$ and embedded in high-quality paraffin wax. To analyze the testicular morphology, the samples were stained with hematoxylin-eosin (HE) and viewed under the microscope (BX51, Olympus, Tokyo, Japan). Additionally, using the $\mathrm{H}-7500$ transmission electron microscope, six testicular tissue samples were selected for transmission electron microscopy (TEM). The detailed procedure was based on the method described in the previous study[53].

\section{ELISA analysis}

The protein expression levels of IL-17A, IL-17RA, IL-17RC, IL-6, IL-23, IL-1 $\beta$, TGF- $\beta$, IFN- $\gamma$ and TNF- $\alpha$ in the interstitial fluid of testes, and the testosterone level in serum were determined by ELISA Kit based on the manufacturer's instructions (Elabscience Biotechnology Co., Ltd. China).

\section{Total protein extraction and Western blotting}

The frozen testes were homogenized using the RIPA buffer (high) and PMSF, then the supernatant was centrifuged at $12,000 \mathrm{~g}$ for $10 \mathrm{~min}$ at $4^{\circ} \mathrm{C}$, and finally collected as the protein extract. With an equal amount of protein, all samples were used in the polyacrylamide modified gel. The proteins were then transferred to a nitrocellulose (NC) membrane for $90 \mathrm{~min}$ at $60 \mathrm{~V}$. Next, the membranes were blocked using a TBS-T with $5 \%$ fat-free milk powder for $2 \mathrm{~h}$ at room temperature, and then probed with anti- $\beta$ actin, anti-IL-17A, anti-IL-17R, anti-Act1, anti-NF-KB, anti-C/EBP-a, anti-TRAF6, anti-ARK1C3, anti-SHD and anti-CYP11A1 antibodies (Affinity Biosciences, China 1:200) overnight at $4^{\circ} \mathrm{C}$. After three washes, the NC membranes were incubated for $12 \mathrm{~h}$ at $4^{\circ} \mathrm{C}$ with the appropriate horseradish peroxidase (HRP)conjugated secondary antibodies (Affinity Biosciences, China 1:2000) diluted in TBS-T. After 3 times washing with TBS-T buffer, the target protein bands were observed by enhanced chemiluminescent (ECL, Affinity Biosciences, China). Optical density was calculated using the Alpha View software (Version: 3.2.2.0) on the FluorChem Q system (Alphalnnotech, CA, USA).

\section{Immunohistochemistry}

To measure the apoptosis in the testes, we used the immunohistochemistry to analyze the protein levels of caspase-3 and caspase-9. The procedures followed a strictly standard protocol by following the immunohistochemistry kit. Finally, light microscopy was performed to observe the location of the target proteins (BOSTER Biological Technology Co. Ltd. China).

\section{Culture of TM3 Leydig cells and detection of testosterone secretion related genes}

The TM3 Leydig cell line (Cell bank of Chinese Academy of Sciences) was cultured in DMEM/F-12 medium. The TM3 cell density was adjusted to a final concentration of $6 \times 103$ cells/well and treated with 
$10 \mathrm{mg} / \mathrm{L} \mathrm{NaF}$ or/and $5 \mathrm{ng} / \mathrm{mL}$ IL-17A for 24 hours. The TM3 Leydig cells were collected to extract the

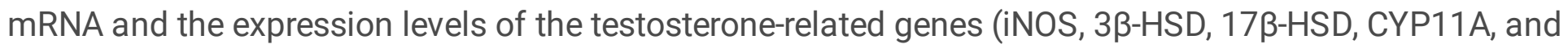
STAR) were analyzed.

\section{Apoptosis assay}

TM3 Leydig cells were also treated with $2 \mathrm{mg} / \mathrm{L} \mathrm{NaF}$ and/or $1 \mathrm{ng} / \mathrm{mL}$ IL-17A for $24 \mathrm{~h}$. The ratio of apoptotic cells was analyzed using FITC-Annexin-V and propidium iodide (PI) staining kit (Beyotime Biotechnology, China) in the flow cytometric analysis. Data were obtained and analyzed using a FACSCalibur II and Cellquset software, respectively.

\section{Statistical analysis}

All the data were expressed as mean \pm S.E.M and analyzed with GraphPad Prism 5.0 software. Differences between treatment groups were calculated using the one-way analysis of variance followed by Dunnett's test. The $p$-value less than 0.05 was considered significant $\left({ }^{\star} p<0.05 ;{ }^{* \star} p<0.01\right)$.

\section{Abbreviations}

ANOVAC

Analysis of variance

BTB

blood-testes barrier

ELISA

Enzyme linked immunosorbent assay

FBS

Fetal bovine serum

$\mathrm{F}$

fluoride

IL-17A

interleukin 17A

IL-17A-/-

IL-17Aknockout

$\mathrm{HE}$

hematoxylin-eosin

$\mathrm{NaF}$

Sodium fluoride

PI

propidium iodide

PMSFP

henylmethylsulfonyl fluoride

TISAB 
Total Ionic Strength Adjustment Buffer

TEM

Transmission electron microscopy

WT

wild type

\section{Declarations}

\section{Acknowledgments}

This work is supported by National Natural Science Foundation of China (Grant No. 31672623) and Veterinary Environmental Lab (Shanxi Key Lab).

\section{Funding}

This work was funded by National Natural Science Foundation of China (Grant No. 31672623) "Role of IL-17A mediated immunoresponse in inflammatory reaction in testis of fluorosed animals"

\section{Author information}

Affiliations

Shanxi Key Laboratory of Environmental Veterinary Medicine; College of Animal Science and Veterinary Medicine, Shanxi Agricultural University. Taigu, Shanxi 030801, PR China

Yanyan Li, Yangfei Zhao, Jinming Wang, Min Cheng, Jundong Wang

\section{Contributions}

Yanyan Li and Yangfei Zhao designed the experiments, contributed to data analysis and interpretation. Yanyan Li wrote the manuscript and Yangfei Zhao, Jinming Wang, Min Cheng, contributed to the structuring and writing of the manuscript. Yanyan Li performed all in vitro experimental work and, Yanyan $\mathrm{Li}$, Yangfei Zhao and Min Cheng performed in vivo experimental work. All authors read and approved the manuscript.

\section{Corresponding authors}

Correspondence to Jundong Wang.

\section{Ethics declarations}

Ethics approval and consent to participate

All animal experiments were approved by China Association For Ethical Studies, 


\section{Consent for publication}

Not applicable.

\section{Competing interests}

The authors declare that they have no competing interests.

Additional information

Publisher's Note

Springer Nature remains neutral with regard to jurisdictional claims in published maps and institutional affiliations.

\section{References}

1. Buzalaf MAR. Review of Fluoride Intake and Appropriateness of Current Guidelines. Adv Dent Res. 2018;29 2:157-66; doi: 10.1177/0022034517750850.

2. Dhar V, Bhatnagar M. Physiology and toxicity of fluoride. Indian J Dent Res. 2009;20 3:350-5; doi: 10.4103/0970-9290.57379.

3. Sun Z, Li S, Guo Z, Li R, Wang J, Niu R, et al. Effects of Fluoride on SOD and CAT in Testis and Epididymis of Mice. Biol Trace Elem Res. 2018;184 1:148-53; doi: 10.1007/s12011-017-1181-1.

4. Wei Q, Deng H, Cui H, Fang J, Zuo Z, Deng J, et al. A mini review of fluoride-induced apoptotic pathways. Environ Sci Pollut Res Int. 2018;25 34:33926-35; doi: 10.1007/s11356-018-3406-Z.

5. Zhang J, Zhu Y, Shi Y, Han Y, Liang C, Feng Z, et al. Fluoride-Induced Autophagy via the Regulation of Phosphorylation of Mammalian Targets of Rapamycin in Mice Leydig Cells. J Agric Food Chem. 2017;65 40:8966-76; doi: 10.1021/acs.jafc.7b03822.

6. Huo M, Han H, Sun Z, Lu Z, Yao X, Wang S, et al. Role of IL-17 Pathways in Immune Privilege: A RNA Deep Sequencing Analysis of the Mice Testis Exposure to Fluoride. Sci Rep. 2016;6:32173; doi: 10.1038/srep32173.

7. He X, Sun Z, Manthari RK, Wu P, Wang J. Fluoride altered rat's blood testis barrier by affecting the Factin via IL-1alpha. Chemosphere. 2018;211:826-33; doi: 10.1016/j.chemosphere.2018.08.009.

8. Wu P, Sun Z, Lv X, Pei X, Manthari RK, Wang J. Fluoride Induces Autoimmune Orchitis Involved with Enhanced IL-17A Secretion in Mice Testis. J Agric Food Chem. 2019;67 48:13333-43; doi: 10.1021/acs.jafc.9b05789.

9. Duan YG, Yu CF, Novak N, Bieber T, Zhu CH, Schuppe HC, et al. Immunodeviation towards a Th17 immune response associated with testicular damage in azoospermic men. Int J Androl. 2011;34 $6 \mathrm{Pt}$ 2:e536-45; doi: 10.1111/j.1365-2605.2010.01137.x.

10. Perez CV, Pellizzari EH, Cigorraga SB, Galardo MN, Naito M, Lustig L, et al. IL17A impairs blood-testis barrier integrity and induces testicular inflammation. Cell Tissue Res. 2014;358 3:885-98; doi: 
10.1007/s00441-014-1995-5.

11. Pramanik S, Saha D. The genetic influence in fluorosis. Environ Toxicol Pharmacol. 2017;56:157-62; doi: 10.1016/j.etap.2017.09.008.

12. Lussi A, Buzalaf MAR, Duangthip D, Anttonen V, Ganss C, Joao-Souza SH, et al. The use of fluoride for the prevention of dental erosion and erosive tooth wear in children and adolescents. Eur Arch Paediatr Dent. 2019;20 6:517-27; doi: 10.1007/s40368-019-00420-0.

13. O'Mullane DM, Baez RJ, Jones S, Lennon MA, Petersen PE, Rugg-Gunn AJ, et al. Fluoride and Oral Health. Community Dent Health. 2016;33 2:69-99.

14. Wiegand A, Buchalla W, Attin T. Review on fluoride-releasing restorative materials-fluoride release and uptake characteristics, antibacterial activity and influence on caries formation. Dent Mater. 2007;23 3:343-62; doi: 10.1016/j.dental.2006.01.022.

15. Boiocchi M, Del Boca L, Gomez DE, Fabbrizzi L, Licchelli M, Monzani E. Nature of urea-fluoride interaction: incipient and definitive proton transfer. J Am Chem Soc. 2004;126 50:16507-14; doi: 10.1021/ja045936c.

16. Zhao Y, Li Y, Wang J, Manthari RK, Wang J. Fluoride induces apoptosis and autophagy through the IL-17 signaling pathway in mice hepatocytes. Arch Toxicol. 2018;92 11:3277-89; doi: 10.1007/s00204-018-2305-x.

17. Dong C, Cao J, Cao C, Han Y, Wu S, Wang S, et al. Effects of fluoride and aluminum on expressions of StAR and P450scc of related steroidogenesis in guinea pigs' testis. Chemosphere. 2016;147:345-51; doi: 10.1016/j.chemosphere.2015.12.064.

18. Han H, Sun Z, Luo G, Wang C, Wei R, Wang J. Fluoride exposure changed the structure and the expressions of reproductive related genes in the hypothalamus-pituitary-testicular axis of male mice. Chemosphere. 2015;135:297-303; doi: 10.1016/j.chemosphere.2015.04.012.

19. Liu Y, Liang C, Gao Y, Jiang S, He Y, Han Y, et al. Fluoride Interferes with the Sperm Fertilizing Ability via Downregulated SPAM1, ACR, and PRSS21 Expression in Rat Epididymis. J Agric Food Chem. 2019;67 18:5240-9; doi: 10.1021/acs.jafc.9b01114.

20. Iwakura $Y$, Nakae S, Saijo S, Ishigame $H$. The roles of IL-17A in inflammatory immune responses and host defense against pathogens. Immunol Rev. 2008;226:57-79; doi: 10.1111/j.1600065X.2008.00699.x.

21. Babaie F, Hasankhani M, Mohammadi H, Safarzadeh E, Rezaiemanesh A, Salimi R, et al. The role of gut microbiota and IL-23/IL-17 pathway in ankylosing spondylitis immunopathogenesis: New insights and updates. Immunol Lett. 2018;196:52-62; doi: 10.1016/j.imlet.2018.01.014.

22. Herjan T, Hong L, Bubenik J, Bulek K, Qian W, Liu C, et al. IL-17-receptor-associated adaptor Act1 directly stabilizes mRNAs to mediate IL-17 inflammatory signaling. Nat Immunol. 2018;19 4:354-65; doi: 10.1038/s41590-018-0071-9.

23. Isailovic N, Daigo K, Mantovani A, Selmi C. Interleukin-17 and innate immunity in infections and chronic inflammation. J Autoimmun. 2015;60:1-11; doi: 10.1016/j.jaut.2015.04.006. 
24. Gravallese EM, Schett G. Effects of the IL-23-IL-17 pathway on bone in spondyloarthritis. Nat Rev Rheumatol. 2018;14 11:631-40; doi: 10.1038/s41584-018-0091-8.

25. Wu L, Chen X, Zhao J, Martin B, Zepp JA, Ko JS, et al. A novel IL-17 signaling pathway controlling keratinocyte proliferation and tumorigenesis via the TRAF4-ERK5 axis. J Exp Med. 2015;212 10:1571-87; doi: 10.1084/jem.20150204.

26. Inoue M, Baba T, Morohashi KI. Recent progress in understanding the mechanisms of Leydig cell differentiation. Mol Cell Endocrinol. 2018;468:39-46; doi: 10.1016/j.mce.2017.12.013.

27. Orta Yilmaz B, Korkut A, Erkan M. Sodium fluoride disrupts testosterone biosynthesis by affecting the steroidogenic pathway in TM3 Leydig cells. Chemosphere. 2018;212:447-55; doi:

10.1016/j.chemosphere.2018.08.112.

28. Duan L, Zhu J, Wang K, Zhou G, Yang Y, Cui L, et al. Does Fluoride Affect Serum Testosterone and Androgen Binding Protein with Age-Specificity? A Population-Based Cross-Sectional Study in Chinese Male Farmers. Biol Trace Elem Res. 2016;174 2:294-9; doi: 10.1007/s12011-016-0726-z.

29. Jackson VJ, Yosaatmadja Y, Flanagan JU, Squire CJ. Structure of AKR1C3 with 3-phenoxybenzoic acid bound. Acta Crystallogr Sect F Struct Biol Cryst Commun. 2012;68 Pt 4:409-13; doi: $10.1107 /$ s1744309112009049.

30. Strauss JF, 3rd. Some new thoughts on the pathophysiology and genetics of polycystic ovary syndrome. Ann N Y Acad Sci. 2003;997:42-8; doi: 10.1196/annals.1290.005.

31. Cao J, Chen Y, Chen J, Yan H, Li M, Wang J. Fluoride exposure changed the structure and the expressions of $Y$ chromosome related genes in testes of mice. Chemosphere. 2016;161:292-9; doi: 10.1016/j.chemosphere.2016.06.106.

32. Oyeyipo IP, Raji Y, Emikpe BO, Bolarinwa AF. Effects of oral administration of nicotine on organ weight, serum testosterone level and testicular histology in adult male rats. Niger J Physiol Sci. 2010;25 1:81-6.

33. Chakradhar S. Puzzling over privilege: How the immune system protects-and fails-the testes. Nat Med. 2018;24 1:2-5; doi: 10.1038/nm0118-2.

34. Ahmed S, Misra DP, Agarwal V. Interleukin-17 pathways in systemic sclerosis-associated fibrosis. Rheumatol Int. 2019;39 7:1135-43; doi: 10.1007/s00296-019-04317-5.

35. Bonneville M, O'Brien RL, Born WK. Gammadelta T cell effector functions: a blend of innate programming and acquired plasticity. Nat Rev Immunol. 2010;10 7:467-78; doi: 10.1038/nri2781.

36. Kim ES, Kim SW, Moon CM, Park JJ, Kim TI, Kim WH, et al. Interactions between IL17A, IL23R, and STAT4 polymorphisms confer susceptibility to intestinal Behcet's disease in Korean population. Life Sci. 2012;90 19-20:740-6; doi: 10.1016/j.lfs.2012.03.017.

37. Hong MJ, Gu BH, Madison MC, Landers C, Tung HY, Kim M, et al. Protective role of gammadelta T cells in cigarette smoke and influenza infection. Mucosal Immunol. 2018;11 3:894-908; doi: 10.1038/mi.2017.93.

38. Paul S, Lal G. Regulatory and effector functions of gamma-delta (gammadelta) T cells and their therapeutic potential in adoptive cellular therapy for cancer. Int J Cancer. 2016;139 5:976-85; doi: 
10.1002/ijc.30109.

39. Choi M, Kim MO, Lee J, Jeong J, Sung Y, Park S, et al. Hepatic serum amyloid A1 upregulates interleukin-17 (IL-17) in gammadelta T cells through Toll-like receptor 2 and is associated with psoriatic symptoms in transgenic mice. Scand J Immunol. 2019;89 6:e12764; doi:

10.1111/sji.12764.

40. Wei R, Luo G, Sun Z, Wang S, Wang J. Chronic fluoride exposure-induced testicular toxicity is associated with inflammatory response in mice. Chemosphere. 2016;153:419-25; doi: 10.1016/j.chemosphere.2016.03.045.

41. Alfano M, Ferrarese R, Locatelli I, Ventimiglia E, Ippolito S, Gallina P, et al. Testicular microbiome in azoospermic men-first evidence of the impact of an altered microenvironment. Hum Reprod. 2018;33 7:1212-7; doi: 10.1093/humrep/dey116.

42. Lysiak JJ, Turner SD, Nguyen QA, Singbartl K, Ley K, Turner TT. Essential role of neutrophils in germ cell-specific apoptosis following ischemia/reperfusion injury of the mouse testis. Biol Reprod. 2001;65 3:718-25; doi: 10.1095/biolreprod65.3.718.

43. Voss J, Stermer AR, Ghaffari R, Tiwary R, Richburg JH. MEHP-induced rat testicular inflammation does not exacerbate germ cell apoptosis. Reproduction. 2018;156 1:35-46; doi: 10.1530/rep-18-0093.

44. Brentnall M, Rodriguez-Menocal L, De Guevara RL, Cepero E, Boise LH. Caspase-9, caspase-3 and caspase-7 have distinct roles during intrinsic apoptosis. BMC Cell Biol. 2013;14:32; doi: 10.1186/1471-2121-14-32.

45. Li P, Zhou L, Zhao T, Liu X, Zhang P, Liu Y, et al. Caspase-9: structure, mechanisms and clinical application. Oncotarget. 2017;8 14:23996-4008; doi: 10.18632/oncotarget.15098.

46. Walsh JG, Cullen SP, Sheridan C, Luthi AU, Gerner C, Martin SJ. Executioner caspase-3 and caspase-7 are functionally distinct proteases. Proc Natl Acad Sci U S A. 2008;105 35:12815-9; doi: 10.1073/pnas.0707715105.

47. Ma R, Liu S, Qiao T, Li D, Zhang R, Guo X. Fluoride Inhibits Longitudinal Bone Growth by Acting Directly at the Growth Plate in Cultured Neonatal Rat Metatarsal Bones. Biol Trace Elem Res. 2019; doi: 10.1007/s12011-019-01997-9.

48. Adedara IA, Olabiyi BF, Ojuade TD, Idris UF, Onibiyo EM, Farombi EO. Taurine reverses sodium fluoride-mediated increase in inflammation, caspase-3 activity, and oxidative damage along the brain-pituitary-gonadal axis in male rats. Can J Physiol Pharmacol. 2017;95 9:1019-29; doi: 10.1139/cjpp-2016-0641.

49. Yan X, Feng C, Chen Q, Li W, Wang H, Lv L, et al. Effects of sodium fluoride treatment in vitro on cell proliferation, apoptosis and caspase-3 and caspase- 9 mRNA expression by neonatal rat osteoblasts. Arch Toxicol. 2009;83 5:451-8; doi: 10.1007/s00204-008-0365-z.

50. O'Hara L, McInnes K, Simitsidellis I, Morgan S, Atanassova N, Slowikowska-Hilczer J, et al. Autocrine androgen action is essential for Leydig cell maturation and function, and protects against late-onset Leydig cell apoptosis in both mice and men. Faseb j. 2015;29 3:894-910; doi: 10.1096/fj.14-255729. 
51. Sun S, Wang J, Lu Y, Dai J. Corticosteroid-binding globulin, induced in testicular Leydig cells by perfluorooctanoic acid, promotes steroid hormone synthesis. Arch Toxicol. 2018;92 6:2013-25; doi: 10.1007/s00204-018-2207-y.

52. Li J, Shi Y, Fan H, Li Y, Zhu Y, Lin X, et al. Effects of Fluoride on Surface Structure of Primary Culture Leydig Cells in Mouse. Biol Trace Elem Res. 2018;183 1:123-7; doi: 10.1007/s12011-017-1121-0.

53. Zhao Y, Zhao J, Wang J, Wang J. Fluoride exposure changed the structure and the expressions of HSP related genes in testes of pubertal rats. Chemosphere. 2017;184:1080-8; doi: 10.1016/j.chemosphere.2017.06.030.

\section{Tables}

Table 1 List of Primer sequences used in the present study 


\begin{tabular}{|c|c|c|}
\hline gene & Primers & Accession No. \\
\hline$\beta$-actin, & $\begin{array}{l}\text { forward:5'-TACCACATCCAAGAAGGCAG-3' } \\
\text { reverse:3'-TGCССТCCAATGGATCCTC-5'; }\end{array}$ & NM_031144.2 \\
\hline IL-17A, & reverse:3'-AGCATCTTCTCGACCCTGAA-5' & NM_010552.3 \\
\hline IL-17F & $\begin{array}{l}\text { forward:5'-ATGGTGCTGTCTTCCTGACC-3' } \\
\text { reverse:3'-CAAAACCAGGGCATTTCTGT-5 }\end{array}$ & NM_145856.2 \\
\hline IL-6 & $\begin{array}{l}\text { forward:5'-CCGGAGAGGAGACTTCACAG-3 } \\
\text { reverse:3'-CAGAATTGCCATTGCACAAC-5' }\end{array}$ & NM_001314054.1 \\
\hline IL-17R & $\begin{array}{l}\text { forward:5'-ACCCAAACCACAAATCCAAG-3' } \\
\text { reverse:3'-TGTGTCCAAGGTCTCCACAG-5' }\end{array}$ & NM_008359.2 \\
\hline INF- $\alpha$ & $\begin{array}{l}\text { forward:5'-GCTGAGCTCAAACCCTGGTA-3' } \\
\text { reverse:3'-TATGGAGTGCTGCTGGTCTG-5' }\end{array}$ & NM_177396.1 \\
\hline IL-21 & $\begin{array}{l}\text { forward:TTGCACAGCAGTCTTGAACC } \\
\text { reverse:AGCTTACACCAGTGGCAACC }\end{array}$ & NM_021782.3 \\
\hline IL-23 & $\begin{array}{l}\text { forward:GACTCAGCCAACTCCTCCAGCCAG } \\
\text { reverse:TTGGCACTAAGGGCTCAGTCAGA }\end{array}$ & NM_031252.2 \\
\hline IL-1 $\beta$ & $\begin{array}{l}\text { forward:GCTGCTTCCAAACCTTTGAC } \\
\text { reverse:TTCTCCACAGCCACAATGAG }\end{array}$ & NM_008361.4 \\
\hline STAR & $\begin{array}{l}\text { forward:5'-TGTCTCCCACTGCATAGCTG-3' } \\
\text { reverse:3'-TGTTCGTAGCTGCTGGTGTC-5' }\end{array}$ & NM_011485.5 \\
\hline $3 \beta$-HSD & $\begin{array}{l}\text { forward:5'-TGCAGACAAAGACCAAGGTG-3' } \\
\text { reverse:3'-ACAGCAGCAGTGTGGATGAC-5' }\end{array}$ & NM_013821.3 \\
\hline CYP11A & $\begin{array}{l}\text { forward:5'-TTGGTTCCACTCCTCAAAGC-3' } \\
\text { reverse:3'-CCAAAGTCTTGGCTGGAATC-5' }\end{array}$ & NM_001346787.1 \\
\hline 17ß-HSD & $\begin{array}{l}\text { forward:5'-GATGTGGCTGTCAACTGTGC-3' } \\
\text { reverse:3'-TTGATAACCCGCTGGAAGTC-5' }\end{array}$ & NM_010475.2 \\
\hline iNOS & $\begin{array}{l}\text { forward:5'-CCGAAGCAAACATCACATTCA-3' } \\
\text { reverse:3'-GGTCTAAAGGCTCCGGGCT-5' }\end{array}$ & NM_001313922.1 \\
\hline
\end{tabular}


$\mathbf{A}$
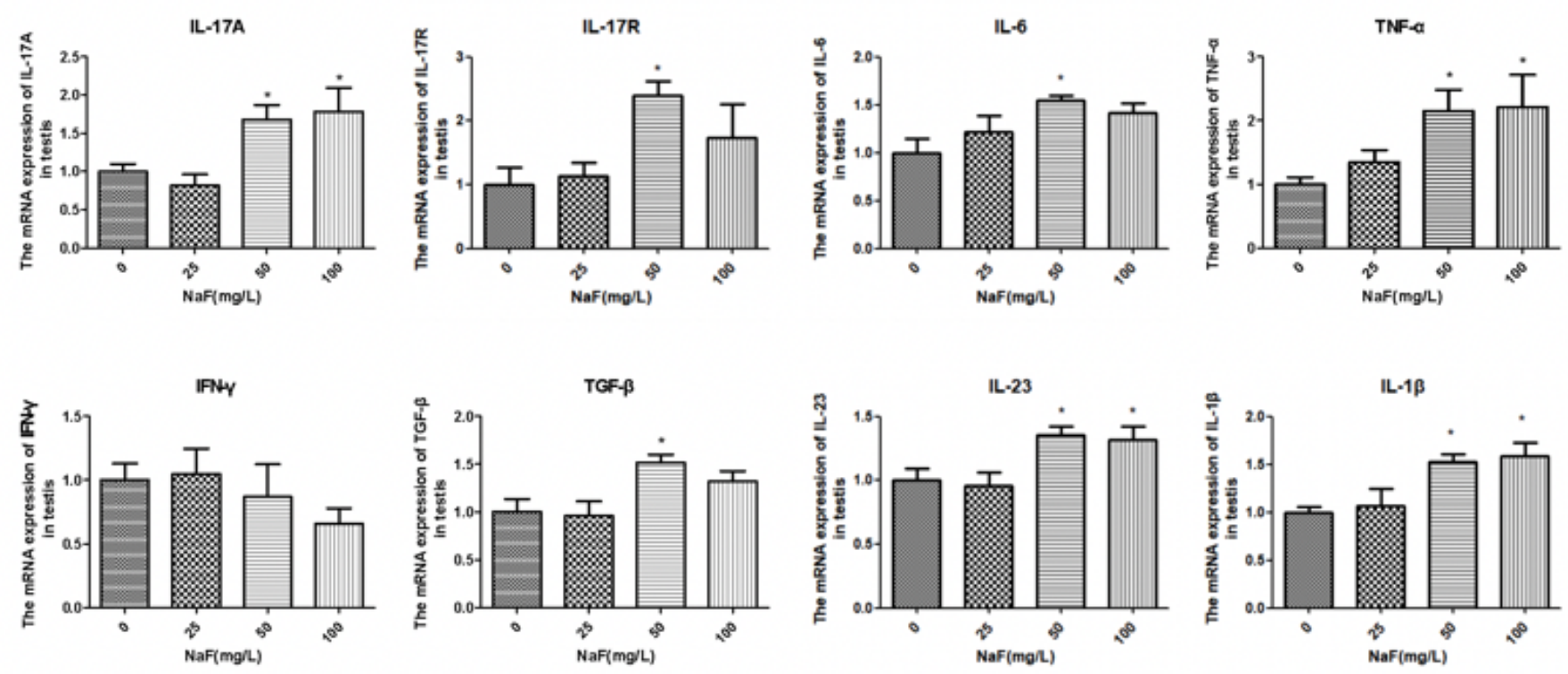

B

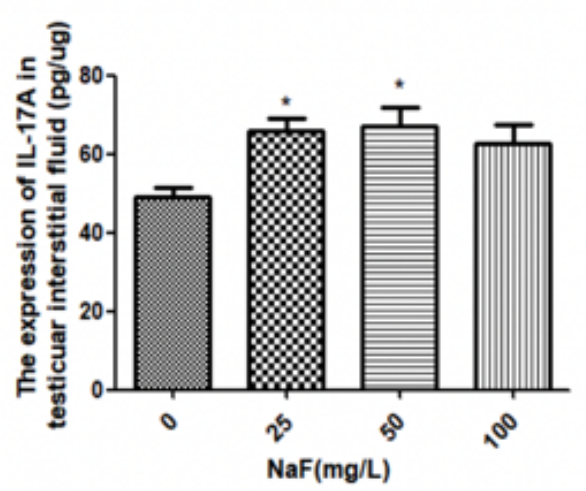

Figure 1

IL-17A is induced by fluorosis in testis (A) mRNA expression levels of IL-17A-related cytokines in the testis of mice ( $n=13$. Three times repetition). (B) Expression of IL-17A in testicular interstitial fluid by ELISA $(n=13$. Three times repetition). Statistical analysis was carried out using one-way ANOVA with Dunnett's test. Error bars denote the mean \pm s.e.m. ${ }^{*} \mathrm{P}<0.05,{ }^{\star *} \mathrm{P}<0.01$. 
$\mathbf{A}$

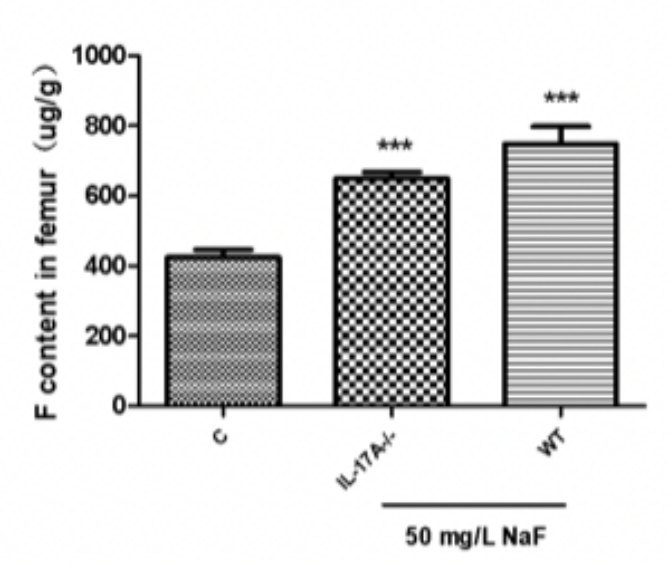

B

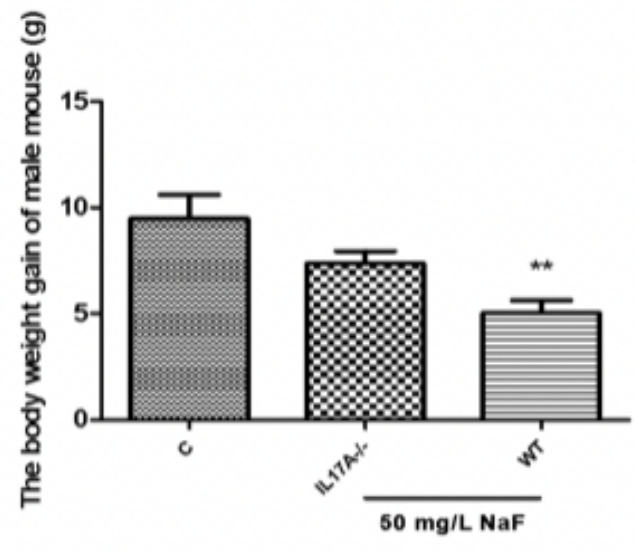

\section{Figure 2}

Successful establishment of fluorosis animal model. (A) The body weight gain of male mice. $(n=13$. Three times repetition). (B) $F$ content in femur ( $n=13$. Three times repetition). Statistical analysis was carried out using one-way ANOVA with Dunnett's test. Error bars denote the mean \pm s.e.m. ${ }^{*} P<0.05$, $\star \star p<0.01$.
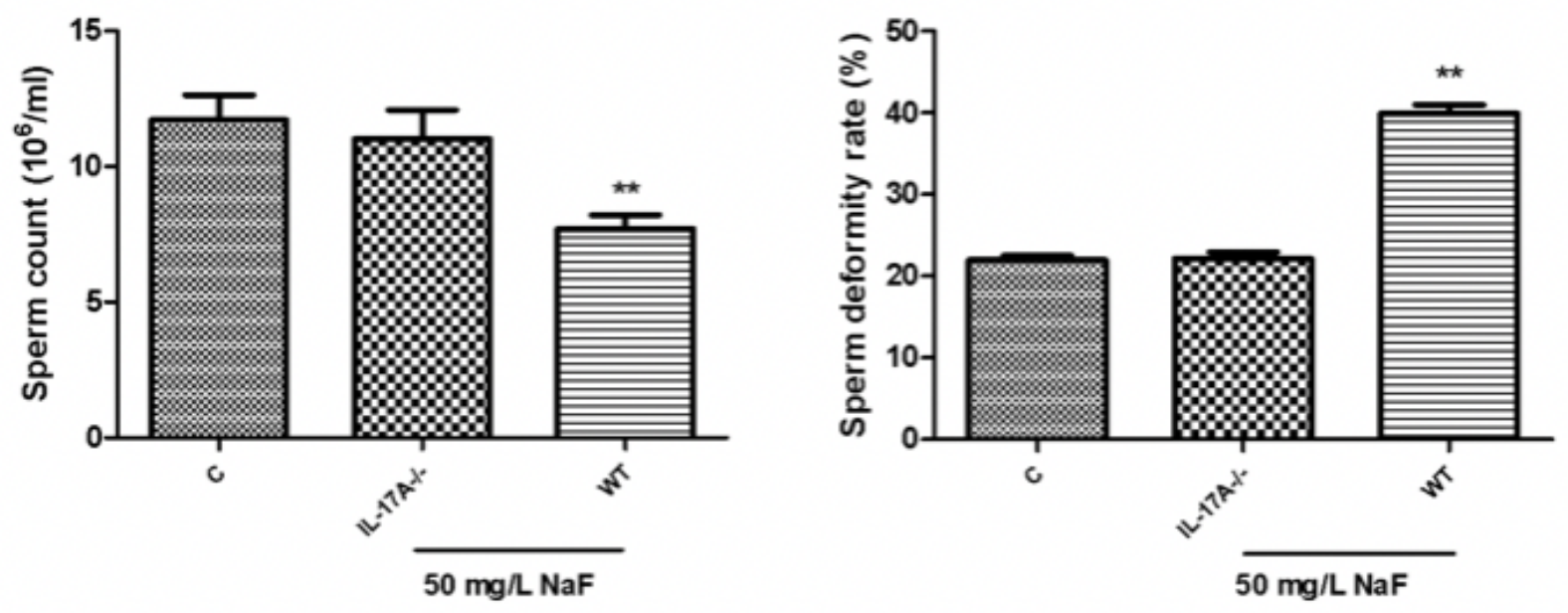

Figure 3 
IL-17A mediates the damage of excessive $F$ to semen quality. (A) Sperm count in testis of mice $(n=13$. Three times repetition). (B) Sperm deformity rate of mice testis ( $n=13$. Three times repetition). Statistical analysis was carried out using one-way ANOVA with Dunnett's test. Error bars denote the mean \pm s.e.m. ${ }^{*} \mathrm{P}<0.05,{ }^{* *} \mathrm{p}<0.01$.

A

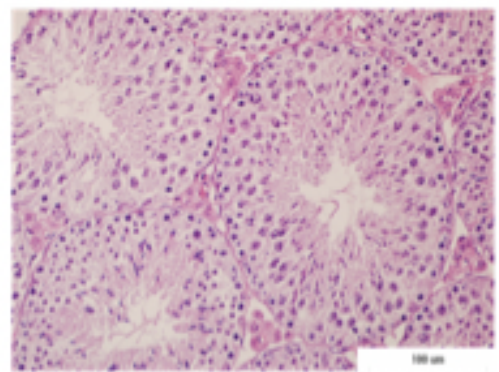

C

B

IL-17A-/-

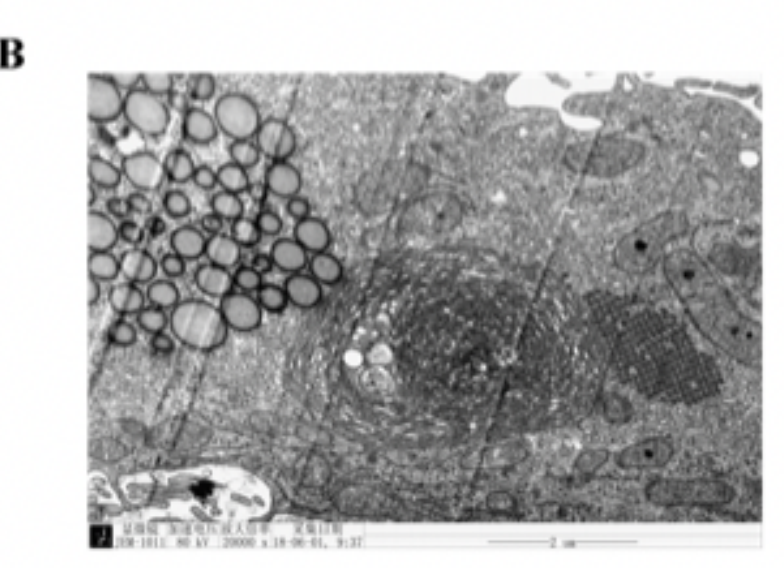

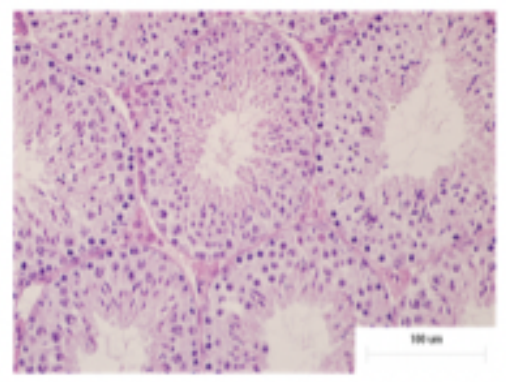

IL-17A-/-

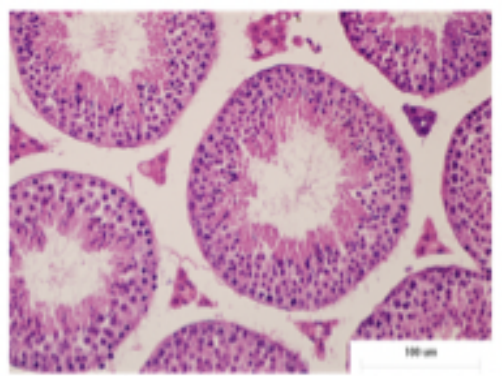

WT
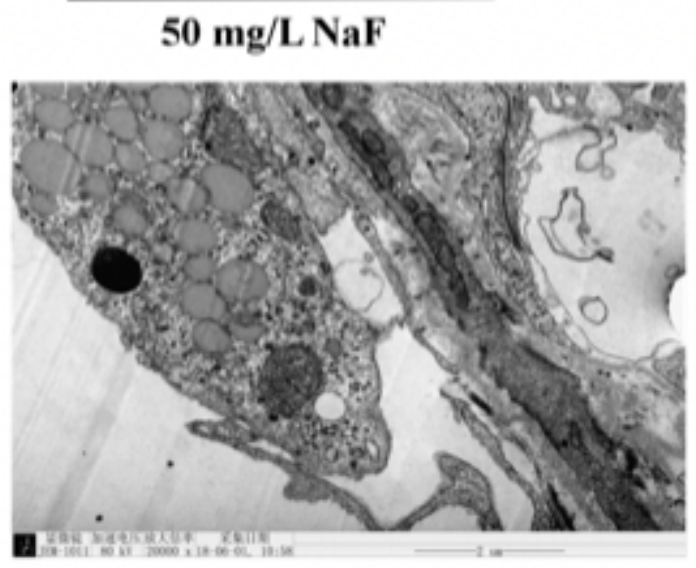

WT

$50 \mathrm{mg} / \mathrm{L} \mathrm{NaF}$

\section{Figure 4}

IL-17A mediates the change of excessive fluoride to histomorphological and ultrastructural in testis of mice . (A) Histological images of the testis of the wild-type and IL-17A-/- mice stained with HE staining.

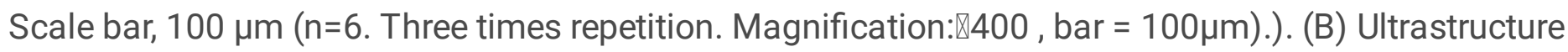

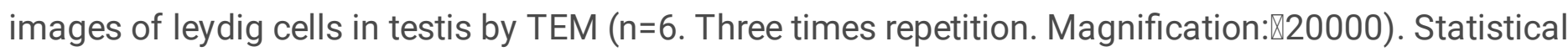
analysis was carried out using one-way ANOVA with Dunnett's test. Error bars denote the mean \pm s.e.m. ${ }^{\star} \mathrm{P}<0.05,{ }^{*} \mathrm{P}<0.01$. 
A

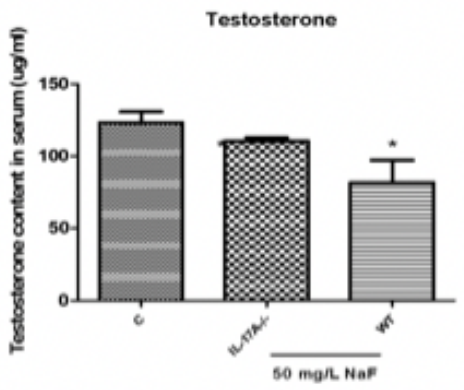

B
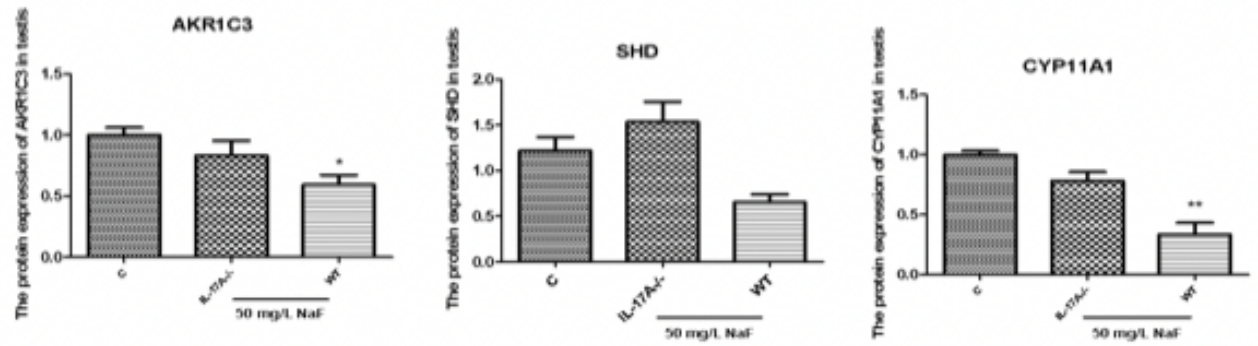

ARK1C3

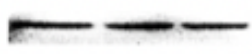

SHD

CYP11A1

$\beta$-actin

\section{Figure 5}

IL-17A mediates the effect of excessive $F$ on the testosterone level in serum of fluorosis mice (A) The content of testosterone in serum of mice ( $n=13$. Three times repetition). (B)the expression of testosterone secretion-related proteins in testis ( $n=13$. Three times repetition). Statistical analysis was carried out using one-way ANOVA with Dunnett's test. Error bars denote the mean \pm s.e.m. ${ }^{*} P<0.05,{ }^{\star \star} P<0.01$. 

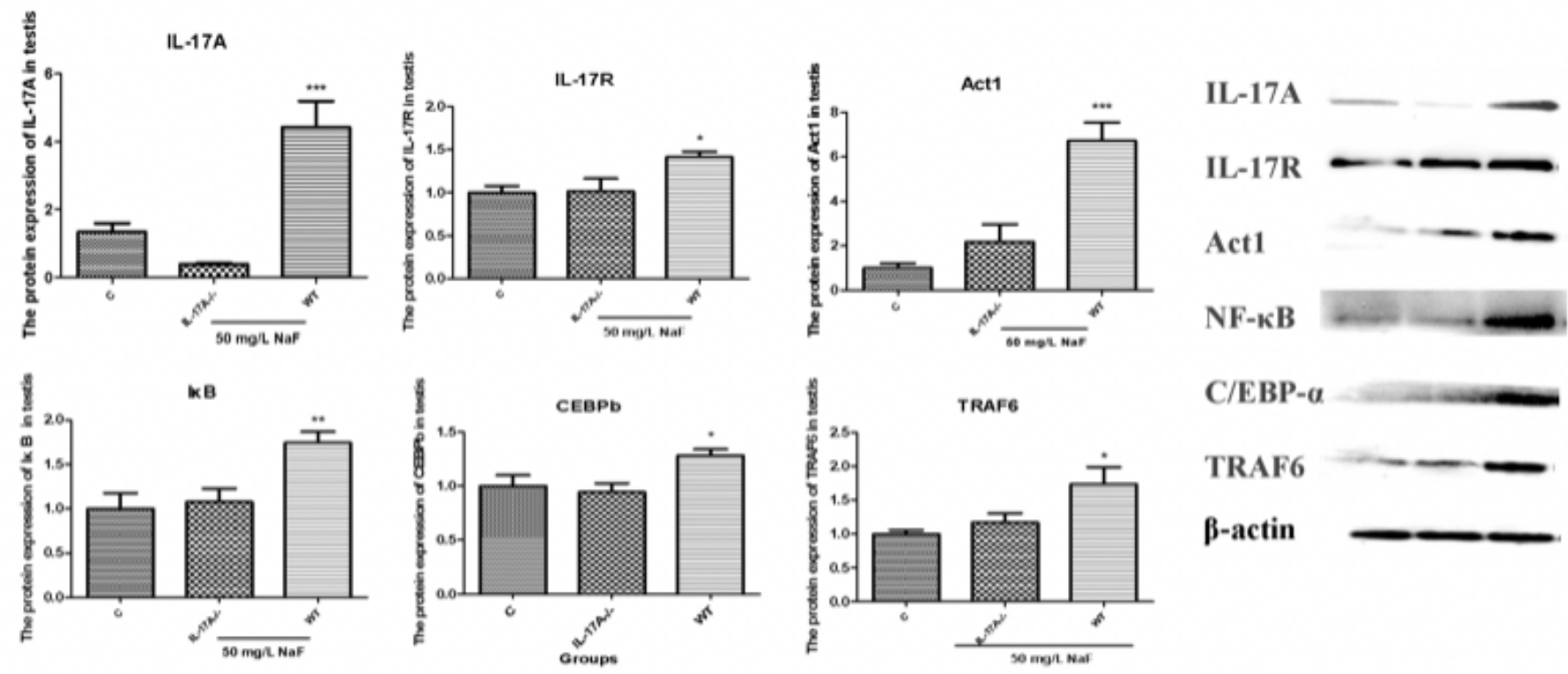

C/EBP- $\alpha$

TRAF6

$\beta$-actin

Figure 6

F can stimulate downstream proteins in IL-17A signal pathway in the testes of fluorosis mice $(n=13$. Three times repetition). Statistical analysis was carried out using one-way ANOVA with Dunnett's test. Error bars denote the mean \pm s.e.m. ${ }^{*} \mathrm{P}<0.05,{ }^{*} \mathrm{P}<0.01$.
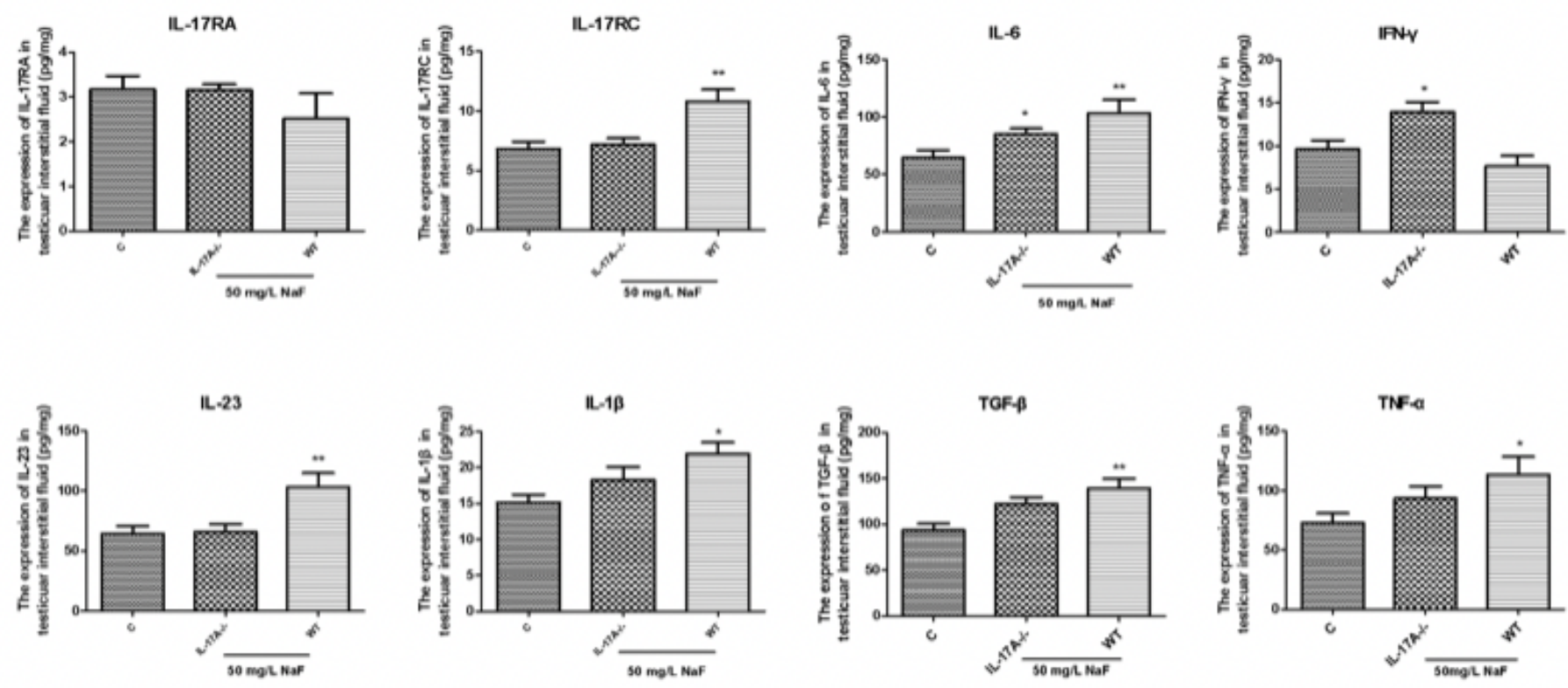


\section{Figure 7}

IL-17A function change have affected the levels of IL-17A secretion-related cytokines in interstitial fluid of testis in fluorosis mice Expressions of IL-17A, IL-17RC, IL-17RA, IL-6, IL-23, IL-1 $\beta$, TGF- $\beta$ and TNF- $\alpha$ in interstitial fluid of testis ( $n=13$. Three times repetition). Statistical analysis was carried out using one-way ANOVA with Dunnett's test. Error bars denote the mean \pm s.e.m. ${ }^{*} P<0.05,{ }^{\star} \times P<0.01$.
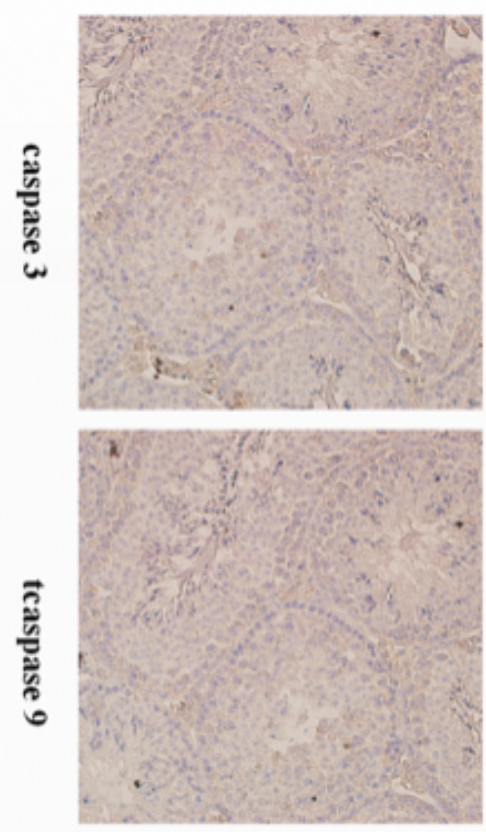

C
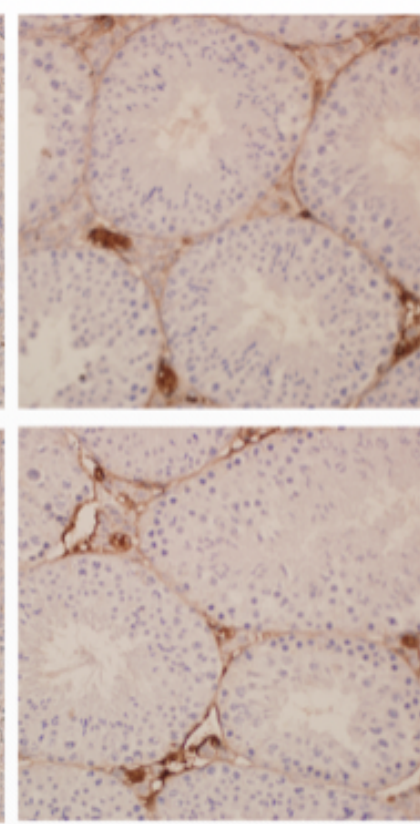

WT
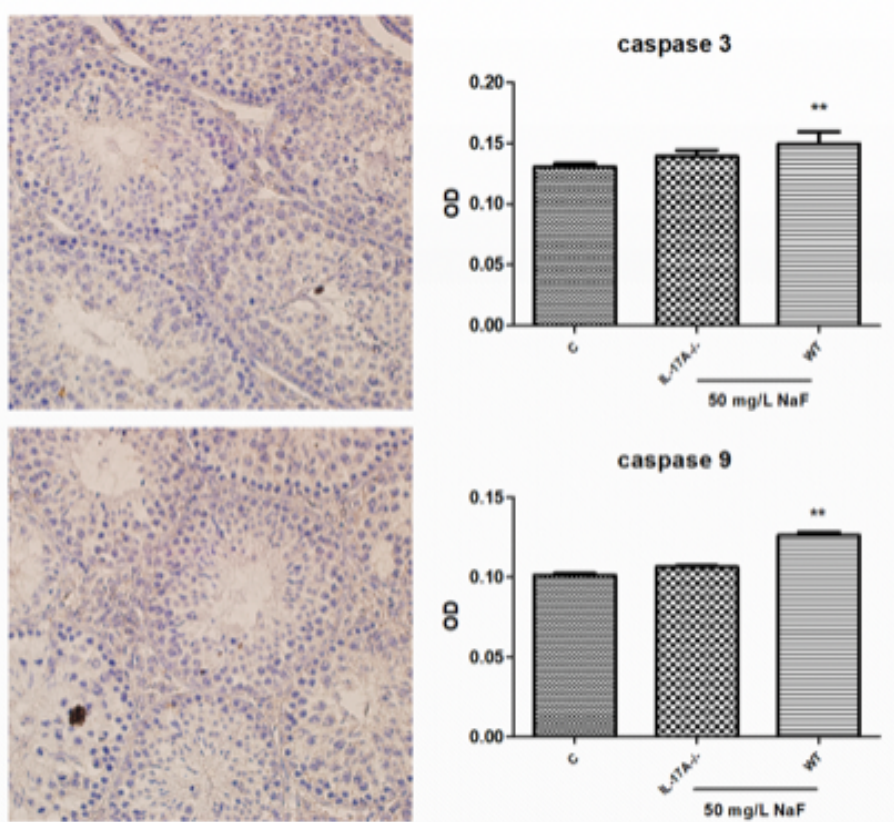

IL-17A-/-

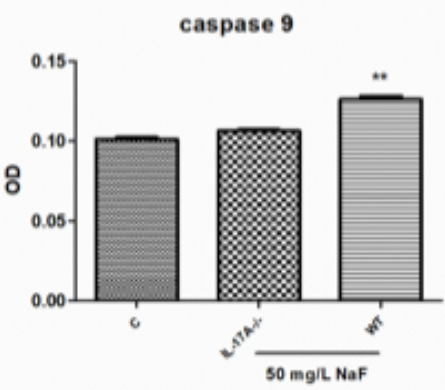

$50 \mathrm{mg} / \mathrm{L} \mathrm{NaF}$

Figure 8

IL-17A amplifies apoptosis of testicular interstitial induced by fluoride. Expressions of caspase-3 and

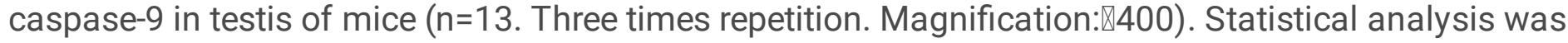
carried out using one-way ANOVA with Dunnett's test. Error bars denote the mean \pm s.e.m. ${ }^{*} P<0.05$, $\star * P<0.01$. 
A
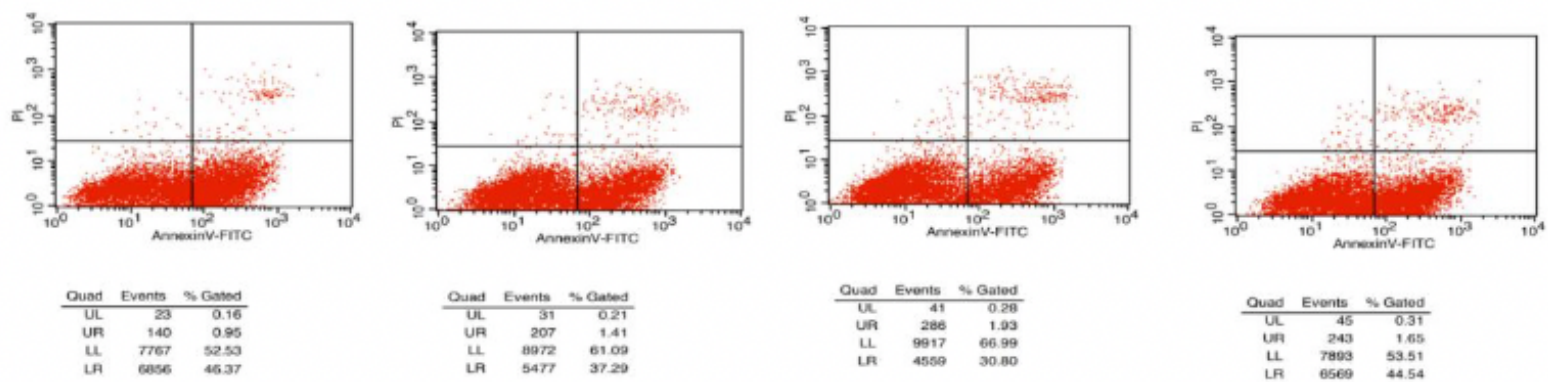

C

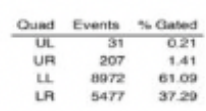

$\mathbf{F}$

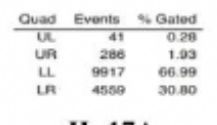

IL-17A

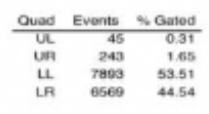

F+IL-17A

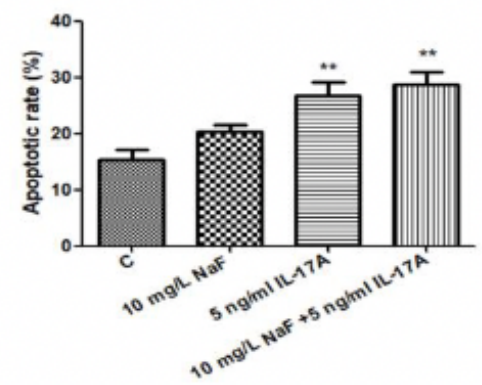

B
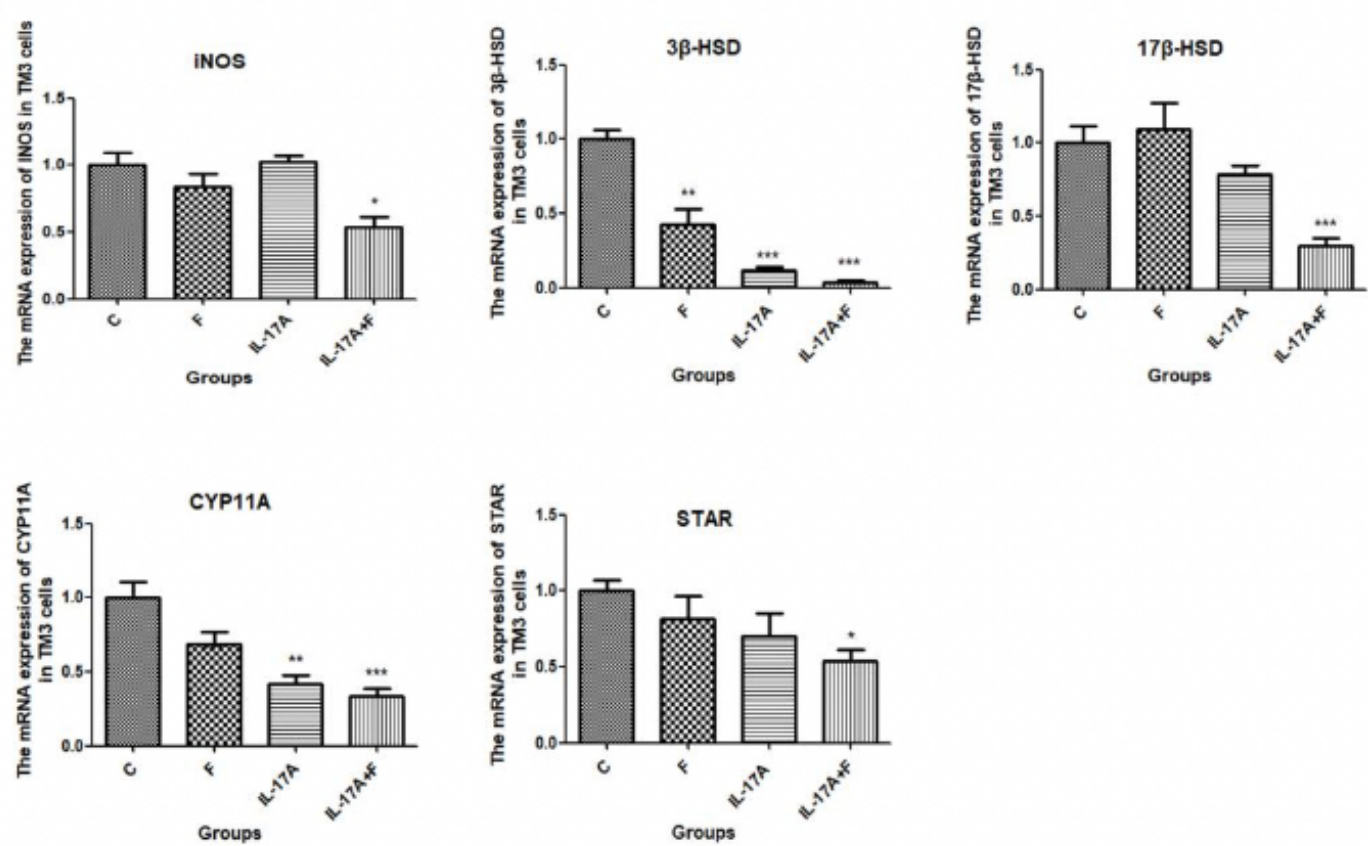

\section{Figure 9}

IL-17A and F Promotes TM3 Leydig Cell Apoptosis and reduces testosterone secretion in vitro (A) apoptotic rate of TM3 Leydig cells ( $n=10$. Three times repetition). (B) mRNA expression levels of testosterone-related in TM3 Leydig cells ( $n=10$. Three times repetition). Statistical analysis was carried out using one-way ANOVA with Dunnett's test. Error bars denote the mean \pm s.e.m. ${ }^{\star} P<0.05,{ }^{\star \star} P<0.01$. 


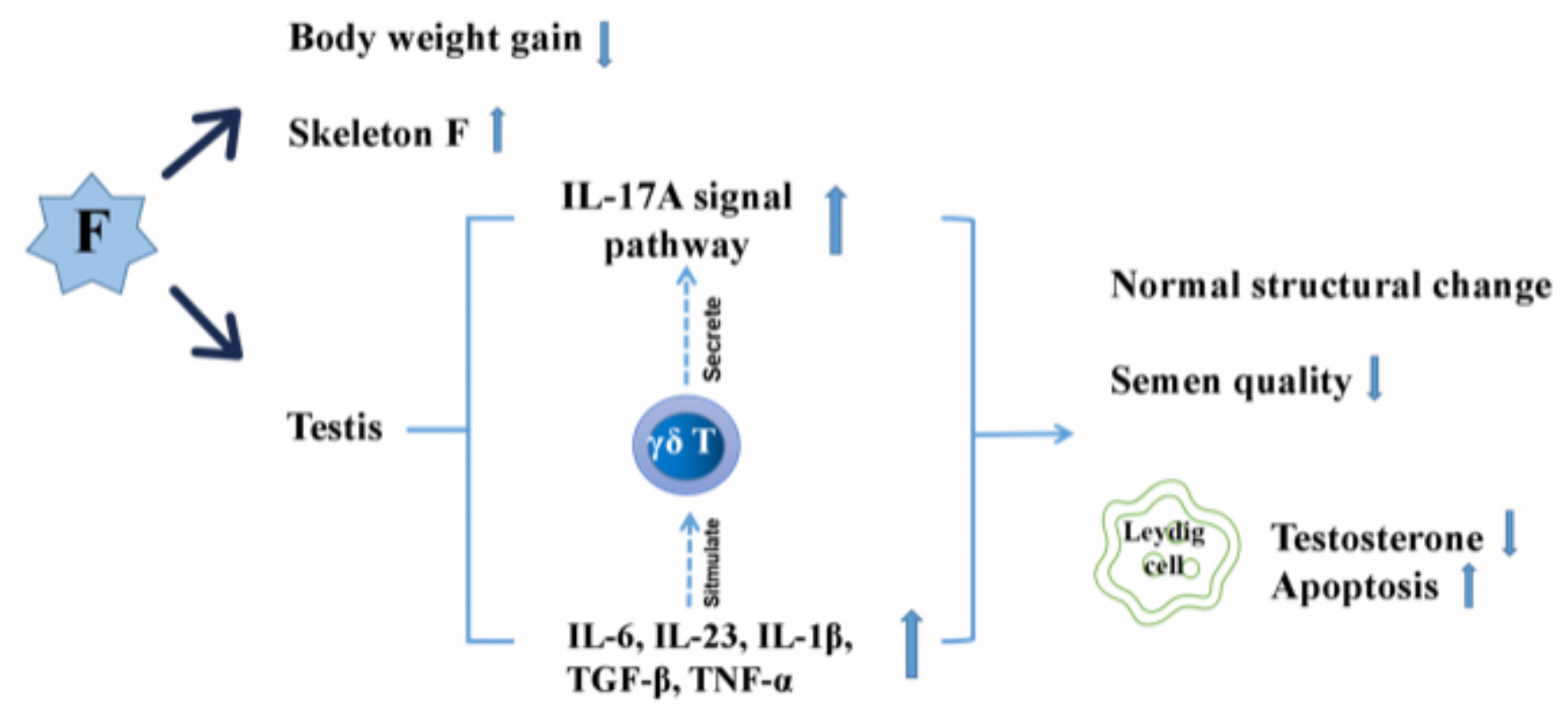

Figure 10

Model of influence of IL-17A for fluoride-induced testis injury by boosting immune response in testis and apoptosis of Leydig cells. IL-17A and its signaling pathway might be involved in the regulation of testicular damage in fluorosis animals and the deletion of IL-17A could abrogate the lesion of testicular fluorosis, including the testicular morphology, semen quality and the ability of testosterone secretion. Additionally, excessive $\mathrm{F}$ intake may evoke immune response in testis and apoptosis of Leydig cells. Therefore, we concluded that Therefore, we concluded that IL-17A deficiency alleviate fluoride-induced injury by inhibiting immune response and apoptosis in testis 